\title{
Determination of influential factors during sample preparation for staphylococcal enterotoxin detection in dairy products
}

\author{
L. Macaluso*, C. Lapeyre and S. Dragacci \\ Ministère de l'Agriculture et de la Pêche, Centre National d'Études Vétérinaires et Alimentaires Paris, \\ 10 rue Pierre Curie, 94704 Maisons Alfort Cedex, France
}

\begin{abstract}
The experimental design method was applied to the study of influential factors on sample preparation for staphylococcal enterotoxin detection in cheese products. Statistical evaluation has shown only one significant factor of food extract composition - concentration by dialysis -. The levels of other factors were chosen in order to have an easy-to-use and optimal preparation procedure before detection.
\end{abstract}

Key words. Experimental designs - extraction procedure - concentration by dialysis - staphylococcal enterotoxins - cheese product.

\section{Introduction}

Staphylococcal food poisoning, due to enterotoxins produced by toxinogenic strains of Staphylococcus aureus, is the second bacterial food-borne illness in France after Salmonella ones [1-3].

Foods involved are usually rich in proteins, like dairy and meat products and egg mixtures.

The microbiological quality of dairy products must respect French regulation [4] and staphylococcal enterotoxin research is engaged in dairy products, contaminated by Staphylococcus aureus with more than $10^{4}$ cells per gramme. If enterotoxins are present, incriminated products are withdrawn from the market.

Therefore, to prevent health problems, it is important to dispose of a reliable and sensitive method for the detection of staphylococcal enterotoxins at a lower threshold than the toxicity level (100 ng/ingestion) [5].

Several immunological methods for the detection and quantification of enterotoxins in foods have been developped, such as the EIA method [6] or commercial kits of detection.

None of them is sensitive enough to detect enterotoxins at a lower level than the toxicity level, in complex matrix like dairy products, because of the incomplete enterotoxins extraction. Therefore, this step must be optimized.

In this present communication, several factors of the sample preparation and extract composition before detection are studied, as well as their influence and the possibilities of sample preparation optimization.

* Correspondence and reprints.

Received March 3, 1998; revised May 22, 1998; accepted May 29, 1998. 


\section{Original articles}

\section{Material and methods}

\section{Material}

\section{Distilled water}

PBS (Phosphate Buffered Saline): sodium phosphate $10 \mathrm{mM}$ (Merck), sodium chloride $0.145 \mathrm{mM}$ (Merck), $\mathrm{pH}=7.4$

PBS Tween: PBS with $0.1 \%$ Tween 20

Sodium hydroxide $5 \mathrm{~N}$ or $1 \mathrm{~N}$ (Merck)

Hydrochloric acid $5 \mathrm{~N}$ or $1 \mathrm{~N}$ (Merck)

Polyethylene glycol 20000 (Merck)

Dialysis tubings: Spectra/Por ${ }^{\circledR}$ molecular porous regenerated cellulose membranes, MWCO 6000-8000 (Poly Labo).

Staphylococcal enterotoxin A (SEA) produced and purified at CNEVA Paris and used for artificial contamination of samples: solution containing 96 ng SEA per mL PBS with $2 \mathrm{mg} / \mathrm{mL}$ BSA (Bovine Serum Albumin) and $0.02 \%$ sodium azide.

Experimental sample: raw milk cheese. Cheese samples are artificially contaminated by $0.3 \mathrm{ng}$ SEA per gramme of cheese.

\section{Methods}

\section{- Preparations of cheese samples}

$12.5 \mathrm{~g}$ of cheese are mixed with $25 \mathrm{~mL}$ of extraction solution using Ultra Turrax. The slurry is artificially contaminated by SEA solution, adjusted to $\mathrm{pH} \leq 4$ with $\mathrm{HCl}$ then centrifuged. The $\mathrm{pH}$ of the supernatant is adjusted to $\mathrm{pH}=7.3 \pm 0.2$ with $\mathrm{NaOH}$, centrifuged and filtered on glass wool. The filtered supernatant is either concentrated or not. Concentration of extracts is carried out by dialysis in tubing against PEG solution at 30\% (30 g of PEG in $100 \mathrm{~mL}$ of distilled water) during one night at $4{ }^{\circ} \mathrm{C}$.

The concentrated extract is recovered and adjusted to $2.5 \mathrm{~mL}$ with PBS.

\section{- Detection of SEA in extract}

Detection of SEA is carried out by indirect double sandwich EIA [6]. Results are determined by measuring absorbance at 405 - $630 \mathrm{~nm}$ using a microtiter plate reader. Then the amount of SEA in extract is calculated from a SEA standard curve.

The absorbance reader is a MR 5000 model (Dynatech).

\section{Preliminary experimental results}

Seven parameters can influence the sample preparation: delipidation of cheese extracts by chloroform, casein precipitation by acidification of samples to $\mathrm{pH} \leq 4$, centrifugation speed, centrifugation temperature, centrifugation time, extraction solution, dialysis of extracts.

\section{Defatting of extracts by chloroform}

Preliminary experiments are carried out to compare two ways of sample delipidation:

1. A delipidation by chloroform,

2. A delipidation by centrifugation at $4{ }^{\circ} \mathrm{C}$.

Statistical evaluation has shown significant differences between the two procedures. Better results, considering SEA recovery, are obtained with the second option. Chloroformic delipidation of extracts is not advisable, because of a loss of enterotoxins.

\section{Acidification of food samples at $\mathrm{pH} \leq 4$}

This step removes lactic caseins in cheese samples by precipitation by decreasing the $\mathrm{pH}$ below the caseins isoelectric point (4.6). Experiments are carried out including and excluding the acidification step. Interfences are observed during the EIA detection of non-acidified extracts. Peroxidase, an endogeneous enzyme of raw milk cheeses, responsible for artefacts and false positive results on EIA, was not involved since it was not identified in the blank samples analysed. Consequently, these interferences could be imputed to lactic caseins.

Therefore, the acidification step is important in sample preparation in order to avoid false positive results.

After carring out these preliminary experiments, five factors are still under study.

\section{Experimental designs method}

The method of fractional experimental designs is applied to study influential factors [7].

1. Centrifugation speed: Centrifugation is performed to separate different components like precipitated caseins, whey proteins and milk fat. Two levels are chosen: $3130 \mathrm{~g}$ and $12500 \mathrm{~g}$.

2. Centrifugation temperature: The melting point of milk fat is between $29{ }^{\circ} \mathrm{C}$ and $34{ }^{\circ} \mathrm{C}$. Two levels of temperature, below the melting point, are chosen: $4{ }^{\circ} \mathrm{C}$ and $20{ }^{\circ} \mathrm{C}$.

3. Centrifugation time: Two levels are chosen: 15 min and $30 \mathrm{~min}$.

4. Extraction solution:

- Distilled water at a temperature $\leq 40{ }^{\circ} \mathrm{C}$, to obtain an efficient dispersion of fat.

- PBS Tween. Tween 20 allows homogeneization of samples.

5. Concentration or no concentration of staphylococcal enterotoxins in extracts by dialysis.

\section{Choice of variables}

The different factors under study are designed by their reduced centered variables $X_{1}, X_{2}, X_{3}, X_{4}$ and $X_{5}$ (variables without dimension). The value -1 represents the low level of a factor, the value +1 , the high level. Therefore, all factors can be treated in the same way. 


\section{Original articles}

\section{Example}

Variable 1: centrifugation speed

Reduced Centered Variable : $X_{1}$
$3130 \mathrm{~g} \quad 12500 \mathrm{~g}$

$\left.\right|_{-1} \quad+1$

\section{Choice of the experimental response}

The main purpose of the study is to evaluate the influence of each factor on the level of SEA $(\mathrm{ng} / \mathrm{mL})$. The other one is to consider interactions between factors.

The experimental response is defined by Y: level of SEA (ng/mL) determined by EIA.

\section{Strategy}

The preparation procedure involves the study of five factors, i.e. $2^{5}=32$ experiments. In order to reduce the theoretical number of experiments from 32 to 8 , the principle of fractional experimental designs is introduced. A fractional design $2^{5-2}$ is therefore applied in our study. The interactions 123 and 13 are chosen to design the factors 4 and 5 : $4=123$ and $5=13$.

The two aliases' independent generators are the following ones: $I=1234$ et $I=135$. The aliases' dependent generator $I=245$ and the aliases' generators group (GGA) $I=1234$ $=135=245$ are obtained by multiplication.

Effects $L_{1}, L_{2}, L_{3}, L_{4}, L_{5}, L_{12}$ and $L_{23}$ are given by the following sums :

$$
L_{1}=E_{1}+E_{234}+E_{35}+E_{1245}
$$

$L$ : effect in the fractional design $2^{5-2}$,

$E$ : effect in the complete design $2^{5}$.

According to the interpretation hypothesis of fractional experimental designs, interactions of degree 3 (between

three factors) and interactions of a degree greater than 3 are not significant. Effects are thus designed by the following relations:

$$
\begin{aligned}
& L_{1}=E_{1}+E_{35} \\
& L_{2}=E_{2}+E_{45} \\
& L_{3}=E_{3}+E_{15} \\
& L_{4}=E_{4}+E_{25} \\
& L_{5}=E_{5}+E_{13}+E_{24} \\
& L_{12}=E_{12}+E_{34} \\
& L_{23}=E_{23}+E_{14} .
\end{aligned}
$$

The experimental matrix is described in table I.

\section{Results and statistical analysis}

The experimental matrix and the matrix of effects obtained after realising the fractional design $2^{5-2}$ are reported in table I.

\section{Statistical evaluation of error and significance of effects}

The method consists in calculating the error on the effect determination and comparing it to the effect itself. The error is defined by the variance $\sigma_{Y}^{2}$ and the standard deviation $\sigma_{Y}$.

\begin{tabular}{|c|c|c|c|c|c|c|c|c|c|c|}
\hline$N^{\circ}$ Experiment & $\begin{array}{c}X_{1} \\
\text { Speed }\end{array}$ & $\begin{array}{c}X_{2} \\
\text { Temperature }\end{array}$ & $\begin{array}{c}X_{3} \\
\text { Time }\end{array}$ & $\begin{array}{c}X_{4} \\
\text { Extraction } \\
\text { solution }\end{array}$ & $\begin{array}{c}X_{5} \\
\text { Concentration } \\
\text { by dialysis }\end{array}$ & $X_{12}$ & $X_{23}$ & $I$ & $\begin{array}{c}Y \\
\text { Amount of detected } \\
\text { SEA }(\mathrm{ng} / \mathrm{mL})\end{array}$ & $\begin{array}{l}\text { Standard } \\
\text { deviation } \\
(\mathrm{ng} / \mathrm{mL})\end{array}$ \\
\hline 1 & - & - & - & - & + & + & + & + & 0.5766 & 0.0729 \\
\hline 2 & + & - & - & + & - & - & + & + & 0.1099 & 0.0225 \\
\hline 3 & - & + & - & + & + & - & - & + & 0.5761 & 0.0882 \\
\hline 4 & + & + & - & - & - & + & - & + & 0.1010 & 0.0311 \\
\hline 5 & - & - & + & + & - & + & - & + & 0.1142 & 0.0480 \\
\hline 6 & + & - & + & - & + & - & - & + & 0.6636 & 0,0756 \\
\hline 7 & - & + & + & - & - & - & + & + & 0.1019 & 0.0287 \\
\hline 8 & + & + & + & + & + & + & + & + & 0.6026 & 0.0316 \\
\hline$\overline{+}$ & $\begin{array}{l}3130 \mathrm{~g} \\
12500 \mathrm{~g}\end{array}$ & $\begin{array}{l}4{ }^{\circ} \mathrm{C} \\
20{ }^{\circ} \mathrm{C}\end{array}$ & $\begin{array}{l}15 \min \\
30 \min \end{array}$ & $\begin{array}{l}\text { PBS Tween } \\
\mathrm{H}_{2} \mathrm{O}_{\mathrm{d}}\end{array}$ & $\begin{array}{l}\text { no } \\
\text { yes }\end{array}$ & & & & & \\
\hline Effect & $\begin{array}{c}L_{1} \\
0.0135\end{array}$ & $\begin{array}{c}L_{2} \\
-0.0103\end{array}$ & $\begin{array}{c}L_{3} \\
0.0148\end{array}$ & $\begin{array}{c}L_{4} \\
-0.005\end{array}$ & $\begin{array}{c}L_{5} \\
0.249\end{array}$ & $\begin{array}{c}L_{12} \\
-0.009\end{array}$ & $\begin{array}{c}L_{23} \\
-0.008\end{array}$ & & & \\
\hline \multicolumn{3}{|c|}{$\sigma_{\mathrm{E}}$} & \multicolumn{2}{|r|}{0.0195} & & & & & & \\
\hline \multicolumn{3}{|c|}{ Confidence interval $\left[-2 \sigma_{\mathrm{E}} ;+2 \sigma_{\mathrm{E}}\right]$} & \multicolumn{2}{|r|}{$[-0.039 ;+0.039]$} & & & & & & \\
\hline
\end{tabular}
In order to obtain the standard deviation $\sigma_{Y}$, the fractional design $2^{5-2}$ was repeated several times. The average variance and the average standard deviation of experimental responses are defined by the following mathematical relations :

$$
\sigma_{Y}{ }^{2}=\frac{\sum_{i=1}^{8}\left[\frac{\sum_{j=1}^{5}\left(Y_{i j}-Y_{m i}\right)^{2}}{n-1}\right]}{N}
$$

Table I. Experimental matrix and matrix of effects of the fractional design $2^{5-2}$. 


$$
\sigma_{Y}=\sqrt{\sigma_{Y}^{2}}
$$

where $i=\mathrm{n}^{\circ}$ of experiment,

$j=\mathrm{n}^{\circ}$ of repetition,

$Y_{m i}=$ average response for each experiment $\mathrm{n}^{\circ} i$

$n=$ number of repetitions for each experiment,

$N=$ number of experiments.

The variance $\sigma_{E}^{2}$ and the standard deviation $\sigma_{E}$ on an effect are defined by the following mathematical relations:

$$
\begin{gathered}
\sigma_{E}^{2}=\frac{\sigma_{Y}^{2}}{N} \\
\sigma_{E}=\sqrt{\sigma_{E}^{2}} .
\end{gathered}
$$

A confidence interval $\pm 2 \sigma_{E}$ is determined in order to define significant effects for a $95 \%$ probability level. The standard deviation $\sigma_{E}$ represents the experimental uncertainty calculated by the average standard deviation of effects. Any effect between $+2 \sigma_{E}$ and $-2 \sigma_{E}$ is assumed to be non significant.

\section{Interpretation}

Results show that effects $L_{1}, L_{2}, L_{3}$ and $L_{4}$ of variables $X_{1}$, $X_{2}, X_{3}$ et $X_{4}$ respectively, are included in the interval $[-0.039 ;+0.039]$. So they are considered to be non significant.

According to an interpretation hypothesis of the fractional designs, if an effect is equal to 0 , each of its terms is equal to 0 as well.

$$
\begin{aligned}
& L_{1}=E_{1}+E_{35} \approx 0 \text { i.e. } E_{1}=0 \text { and } E_{35}=0 \\
& L_{2}=E_{2}+E_{45} \approx 0 \text { i.e. } E_{2}=0 \text { and } E_{45}=0 \\
& L_{3}=E_{3}+E_{15} \approx 0 \text { i.e. } E_{3}=0 \text { and } E_{15}=0 \\
& L_{4}=E_{4}+E_{25} \approx 0 \text { i.e. } E_{4}=0 \text { and } E_{25}=0 .
\end{aligned}
$$

Therefore the effects of the interactions of degree $2-35$, 45, 15 and 25- and the main effects of the variables $X_{1}, X_{2}$, $X_{3}$ et $X_{4}-E_{1}, E_{2}, E_{3}$ and $E_{4}-$ are not significant.

\section{$\geq$ First conclusion:}

Factors 1, 2, 3 and 4 and interactions of each factor with the factor 5 have no influence on the composition of extracts.

In the same way, effects $L_{12}$ and $L_{23}$ are considered to be non significant because included in the interval [ -0.039 ; $+0.039]$. The interactions 12 and 34 are aliased between themselves, just like interactions 23 and 14 (relations 7 and 8).

$$
\begin{aligned}
& L_{12}=E_{12}+E_{34} \approx 0 \text { i.e. } E_{12}=0 \text { and } E_{34}=0 \\
& L_{23}=E_{23}+E_{14} \approx 0 \text { i.e. } E_{23}=0 \text { and } E_{14}=0
\end{aligned}
$$

According to the hypothesis previously reported, the interactions 12, 34, 23 and 14 are not significant.

\section{$\geq$ Second conclusion:}

The interactions 12, 34, 23 and 14 have no influence on the composition of extracts.
Only effect $L_{5}$ of the variable $X_{5}$ does not belong to the interval $[-0.039 ;+0.039]$. Thus, it is considered to be significant.

\section{Interpretation of the main effect $E_{5}$ of the variable $X_{5}$}

In the fractional experimental design $2^{5-2}$, the main effect $E_{5}$ is aliased with effects $E_{13}$ and $E_{24}$.

$$
L_{5}=E_{5}+E_{13}+E_{24}
$$

\section{Interaction 24}

The main effects $E_{2}$ and $E_{4}$ of factors 2 and 4 are not significant.

According to the hypothesis of fractional experimental designs, if two effects are poor, the effect of their interaction is assumed to be low. Moreover, because of a great experience of the extraction procedure, the effect of the interaction 24 is considered to be non significant.

\section{Interaction 13}

According to the hypothesis previously reported, the interaction of the effect 13 can be assumed to be non significant. But data from literature [8] give a mathematical relation between the agglutination speed of fat and the centrifugation speed: an increase of the centrifugation speed produces a decrease of the centrifugation time. Experiments have demonstrated that the effect of the interaction 13 was not significant in the chosen experimental field. In fact, the melting point of milk fat is between $29{ }^{\circ} \mathrm{C}$ and $34{ }^{\circ} \mathrm{C}$ and the centrifugation temperature levels chosen were $4{ }^{\circ} \mathrm{C}$ and $20{ }^{\circ} \mathrm{C}$. These data show that the interaction 13 is not significant in the chosen experimental field.

Because of conclusions previously reported, the main effect $E_{5}$ is no longer aliased with the interactions 13 and 24. It can be written:

$$
E_{5} \approx L_{5}
$$

\section{$\geq$ Third conclusion:}

Factor 5 has the only influential effect on the extract composition. The positive effect of this factor means that the enterotoxins concentration of the extracts, by dialysis, is a necessary and essential step in sample preparation, in order to decrease the detection level of enterotoxins in dairy products.

\section{Choice of factors' level}

\section{Influential factor:}

Factor 5: Concentration by dialysis.

\section{Non influential factors:}

The centrifugation speed will be equal to $12500 \mathrm{~g}$, the temperature to $4{ }^{\circ} \mathrm{C}$, the time equal to $15 \mathrm{~min}$. These levels are chosen so as to obtain an easy-to-use procedure, an optimal separation of components during centrifugation and a gain of time. The chosen extraction solution is distilled water at a temperature $\leq 40{ }^{\circ} \mathrm{C}$. 


\section{Original articles}

\section{Conclusion - discussion}

In this study, we demonstrated that the only influential factor on the sample preparation among the ones that have been tested is the concentration of extracts by dialysis. This step leads to a decrease of the enterotoxins detection level. So the dairy products regulation is more easily respected.

Nevertheless, as the human factor is important in the concentration by dialysis, it might be difficult to transfer this method to other laboratories.

So, in order to optimize sample preparation, to improve the practicability and an easy transfer to other laboratories, the development of a new concentration method must be considered.

\section{Acknowledgment}

We thank Dr. M. Nicolas for helpful advice.

\section{References}

1. Bergdoll, M. S. In: Foodborne Bacterial Pathogens, Michael, P.; Doyle Ed., Marcel Dekker, Inc., New York, 1989; pp 464-513.

2. De Buyser, M. L.; Lapeyre, C.; Dilasser, F.; Janin, F. Coll. Soc. Microbiol./Alim. 1997, 11, 7-16.

3. Haeghebaert, S.; Dlarocque-Astagneau, E.; Vaillant, V.; Le Querrec, F. Bull. Epidémiol. Hebd. ( $\mathrm{N}^{\circ}$ spécial février), 1997; pp 28-30.

4. Arrêté Ministériel du 30 mars 1994 relatif aux critères microbiologiques auxquels doivent satisfaire les laits de consommation et les produits à base de lait lors de leur mise sur le marché (Journal Officiel de la République Française, 21 avril 1994).

5. Reiser, R.; Conaway, D.; Bergdoll, M. S. Applied Microbiol. 1974, 27(1), 83-85.

6. Lapeyre, C.; Janin, F.; Kaveri, S. V. Food Microbiol. 1988, 5, 25-31.

7. Goupy, J. La méthode des Plans d'expériences, optimisation du choix des essais et de l'interprétation des résultats, Dunod Ed., Paris, 1988.

8. Alais, C. Sciences du lait, Principes des techniques laitières, Sepaic Ed., Paris, 1984. 